\title{
GMR
}

\section{Interleukin-27-924A/G gene polymorphism is associated with Rheumatoid Arthritis in Egyptian population}

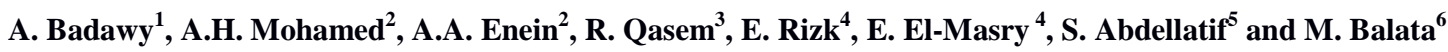

${ }^{1}$ Department of Medical Biochemistry, Faculty of Medicine, Mansoura University, Mansoura, Egypt

${ }^{2}$ Department of Internal Medicine, Faculty of Medicine, Mansoura University, Mansoura, Egypt

${ }^{3}$ Department of Pathology, Faculty of Medicine, Northern Border University, Arar, Saudia Arabia

${ }^{4}$ department of Clinical Pathology, Faculty of Medicine, Mansoura University, Mansoura, Egypt

${ }^{5}$ Department of Rheumatology and Rehabilitation, Faculty of Medicine Al-Azhar University, Cairo, Egypt

${ }^{6}$ Department of Rheumatology and Rehabilitation, Faculty of Medicine, Ain Shams University, Cairo, Egypt.

Corresponding author: Badawy Abdelnaser

E-mail: Abdelnaserbadawy_bio@yahoo.com

Genet. Mol. Res. 17 (2): gmr16039915

Received Feb 12, 2018

Accepted May 01, 2018

Published May 05, 2018

DOI: http://dx.doi.org/10.4238/gmr16039915

Copyright (C) 2018 The Authors. This is an open-access article distributed under the terms of the Creative Commons Attribution ShareAlike (CC BY-SA) 4.0 License.

ABSTRACT. Rheumatoid arthritis (RA) is an autoimmune disease with increasing activity of $\mathrm{T}$ lymphocytes and abnormal production of inflammatory cytokines. Interleukin-27 (IL-27), a multifunction cytokine with contradictory inflammatory effect. Polymorphism of IL-27 was reported to be predisposed to many inflammatory diseases and autoimmune diseases. We aimed to assess the role of IL-27 polymorphism in the predisposition of RA in Egyptian population. A case control study included 100 patients with RA and 100 healthy subjects represented the control group. The IL-27-924A/G gene polymorphism was investigated by RFLP-PCR. The serum level of IL-27was estimated by enzyme-linked immunosorbent assay. The AA genotype was significantly higher in patients with rheumatoid arthritis as compared with the control group ( $\mathrm{P}=0.02$, OR $(95 \%$ $\mathrm{CI})=0.4(0.1-1.2)$. In addition, we observed significant elevation in the level of serum IL-27 in the patients group in comparison with the 
healthy subjects. We found that patients with AA genotype or A allele had significant higher level of serum IL-27. There was positive relationship between the serum level of IL-27 and severity of the disease. It was concluded that AA genotype of IL-27 gene might be a risk factor for the incidence of RA in Egyptian population. Patient with significantly higher blood levels of IL-27 were at risk for increasing disease activity.

Key words: Rheumatoid arthritis; IL-27; Gene polymorphism

\section{INTRODUCTION}

Rheumatoid arthritis (RA) is one of the chronic autoimmune disorders which manifested by joints inflammation and damage (Lai et al., 2016). RA is linked to numerous abnormalities in the immune response, like hyperactive $\mathrm{T}$ lymphocytes and abnormal production of inflammatory cytokines (Sakaguchi and Benham, 2012). Macrophages, T and B cells secrete different types of inflammatory cytokines in the joints leading to their inflammation and finally destruction (Choy and Panayi, 2001\& Linsley and Nadler, 2009). The diseases of autoimmunity are characterized by irregular immune responses, and it has been thought that increased production of many modulators of immune response could potentiate the stimulation and persistence of the inflammatory cells that provoke the progression of autoimmune diseases (Sprent and Surh, 2011).Human IL-27 gene is situated on p11 of chromosome 16 and expressed in the form of heterodimer molecule which is composed of p28 component (like p35) and EB3 component (like p40). IL-27 has dual inflammatory role in the pathogenesis of autoimmune disorder and plays an apparent role in the Th cell responses (Shen et al., 2011). The presence of a large amount of IL-27 at chronic inflammation sites may stimulate the development of arthritis by starting the initial stages of the Th1 differentiation (Tanida et al., 2011). Conversely, the anti-inflammatory role of IL-27 in prevention of organ damage and inflammation occurs by inhibiting the production of IL-2 secretion by Th2 cells, suppressing the differentiation of Th17 and stimulating the secretion of IL-10 (Kamiya et al., 2011). The role of IL27 gene polymorphisms in the development and severity of human diseases has been investigated in limited researches (Trinchieri, 2003).

IL-27, as a pleiotropic gene, can control the proliferation of immature T-cell and have an effective role in activating the secretion of interferon-gamma (Zhao et al., 2009 and Li et al., 2009). Variance of IL-27 gene were declared to be a risk for a diversity of diseases, such as rheumatoid arthritis, cancer ovary, Crohn's disease, colorectal cancer, asthma, nasopharyngeal carcinoma, and esophageal cancer (Huang et al., 2012, Tao et al., 2012 and Zhang et al., 2014) but not with type 1 diabetes mellitus (Tanida et al., 2011). Even though, previous reports had concluded that IL-27 has a great role in the development of RA and its exact mechanism in many immune responses has not been well established. Our aim is to analyze the association of IL-27 genetic polymorphism with RA susceptibility in Egyptian population in a case-control study.

\section{MATERIALS and METHODS}

\section{Study subjects}

The current study included 100 RA patients whom were recruited from the rheumatology and immunology Outpatient Clinic in Mansoura University Hospital, Mansoura University, Egypt. One-hundred healthy adults were selected on voluntary basis and comprised the control group. Diagnosis of RA was based on the criteria established by the ACR diagnostic criteria (Aletaha et al. 2010). All demographic and clinical data, Disease Activity Score in 28 joints (DAS28) and laboratory tests (CBC; erythrocyte sedimentation rate (ESR), CRP, RF and ACPA) were included and recorded. Patients with asthma, inflammatory bowel disease, chronic infections and chronic obstructive pulmonary disease were excluded from the study. The research was approved by ethics committee of Mansoura University and in accordance with the general assembly of the World Medical Association Declaration of Helsinki (Reference number R/17.03.05). A written agreement was taken from each participant.

\section{Blood sample collection}

Five mLs peripheral blood samples were withdrawn from each participant. One mL was collected in EDTA tube for subsequent fresh DNA isolation and the separated DNA was stored at $-80^{\circ} \mathrm{C}$ until the later use for detection of the IL- 
$27-924 \mathrm{~A} / \mathrm{G}$ polymorphism. The remaining $4 \mathrm{mLs}$ blood samples were transferred into blank tubes and left to clot for 15 minutes and the sera were used for the assay of IL-27 level using ELISA technique.

\section{Extraction of DNA and IL-27 - 924 A/G genotyping}

Genomic DNA was obtained from blood samples by DNA purification kit (Qiagen GmbH, Cat No.51104, and Hiden, Germany). Traditional PCR was used for amplification of IL-27 - 924A/G gene as previously described by Paradowska-Gorycka et al. (2014). Two sets of primers sequences were designed for gene amplification: forward 5CTGATCCTGACCTCACTCAACGC3`, reverse 5CTGAC TGGGACTGGGACTCAGC3`. PCR amplification was done according to the following temperature program: Denaturation was initially done at $95^{\circ} \mathrm{C}$ for $15 \mathrm{~min}$, then 35 cycles of: $94^{\circ} \mathrm{C}$ for $45 \mathrm{~s}, 55^{\circ} \mathrm{C}$ for $45 \mathrm{~s}$ and $72^{\circ} \mathrm{C}$ for $45 \mathrm{~s}$, followed by $8 \mathrm{~min}$ at $72^{\circ} \mathrm{C}$ as a final extension. The product of PCR was 119 bp fragment length. For identifying the genotypes of IL-27-924A/G gene, each PCR product was subjected for digestion with $1 \mathrm{U}$ of BstU I restriction enzyme (thermo scientific, USA), the digestion products of restriction enzyme were electrophoresed using $3 \%$ agarose and were compared against 50 bp DNA ladder. The G allele gave 95and 24bp fragments, while the A allele remained uncut.

\section{Estimation of serum IL-27 by ELISA assay}

Serum IL-27 level was assayed by double sandwich enzyme linked immunosorbent assay (Sun Red, Catalog number: 201-12-0076, Germany) according to instructions of manufacturer. The lower limit is $5.521 \mathrm{ng} / \mathrm{L}$ and the detection range is $6.5-2000 \mathrm{ng} / \mathrm{L}$.

\section{Statistical analysis}

Excel program and SPSS version 21 was used to analyze the resulting data. For analysis of quantitative data, MannWhitney test for comparison of two groups, the Wilcoxon test was used to compare the two paired groups and Kruskal Wallis test was used for more than two groups. To compare qualitative data, $\chi 2$ test was used. $\mathrm{P}<0.05$ was considered significant at $95 \%$ confidence interval. The frequencies of genotypes and alleles in both groups were tested for Hardy-Weinberg Equilibrium.

\section{RESULTS}

\section{Clinical and laboratory data in the control and patient groups}

Clinical and biochemical data in the control group and RA patients are shown in Table 1. The serum levels of IL-27 were considerably increased in patients group $(\mathrm{P}<0.0001)$ as compared to healthy group $(390.66 \pm 210.42 \mathrm{ng} / \mathrm{ml}$ and $136.08 \pm 76.00 \mathrm{ng} / \mathrm{ml}$, respectively). In addition, the patients group had high significant values of BMI, DAS28 score, ESR, CRP, RF and ACPA, while mean hemoglobin level was significantly higher in the control group. There was negligible difference between both groups as regards age and gender distribution.

\begin{tabular}{llll}
\hline \multicolumn{2}{|l|}{ Table 1. Clinical and biochemical data in the control group and RA patients } \\
\hline $\begin{array}{l}\text { Disease } \\
\text { duration }\end{array}$ & $-\cdots .35 \pm \mathbf{2 . 3 7}$ & ---- \\
\hline BMI & $26.90 \pm 4.60$ & $28.40 \pm 4.44$ & $\mathbf{0 . 0 2 7}$ \\
\hline DAS -28 & $3.16 \pm 2.26$ & ------ & ---- \\
\hline CRP & $3.04 \pm 0.92$ & $34.36 \pm 17.64$ & $\mathbf{0}$ \\
\hline ESR & $10.29 \pm 3.62$ & $33.92 \pm 16.94$ & $\mathbf{0}$ \\
\hline IL-27 & $136.08 \pm 76.00$ & $390.66 \pm 210.42$ & $\mathbf{0}$ \\
\hline RF & $9.45 \pm 5.86$ & $74.90 \pm 81.01$ & $\mathbf{0}$ \\
\hline ACCP & $3.56 \pm 1.58$ & $129.02 \pm 178.43$ & $\mathbf{0}$ \\
\hline Hb & $11.74 \pm 0.99$ & $10.62 \pm 1.24$ & $\mathbf{0}$ \\
\hline
\end{tabular}




\section{Genotyping of the study population}

The distribution of genotypes and alleles of IL-27 -924A/G gene are represented in Table 2. The distribution of genotypes in both control group and patients group was in Hardy-Weinberg equilibrium $(\mathrm{P}>0.05)$. PCR determination of IL-27 -924A/G gene polymorphism (Figure 1) revealed that, there was higher frequency of AA genotype in patients with rheumatoid arthritis as compared with the controls $(\mathrm{P}=0.02, \mathrm{OR}(95 \% \mathrm{CI})=0.4(0.1-1.2)$. In the dominant model, the risk for development of RA was increased in individuals with AA genotype $(\mathrm{P}=0.02, \mathrm{OR}$ $(95 \% \mathrm{CI})=2.4(1.1-5.4)$.

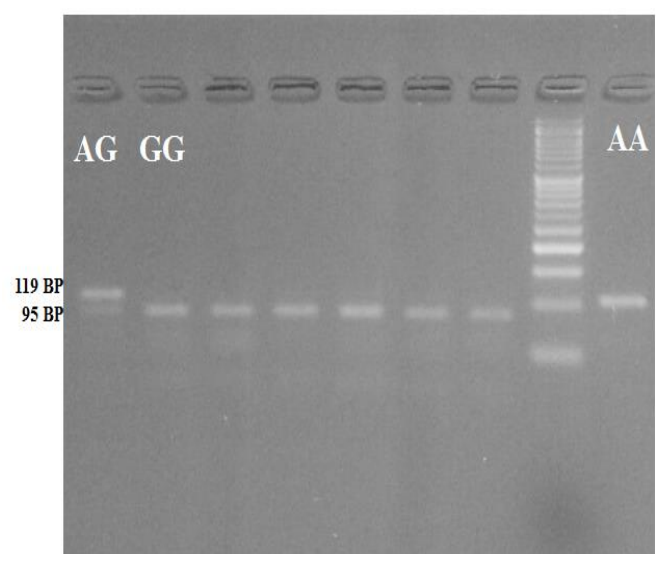

Figure 1. Agarose gel electrophoresis showing the enzymatic digestion of IL-27 -924 A/G gene polymorphism using 50-bp DNA size ladder labeled from bottom up (50,100, 150...). AA genotype (119bp), AG genotype (119, 95,24bp) and GG genotype (95,24bp). The 24 base pairs band runs out of the gel.

Table 2. Distribution of genotypes and alleles of IL-27 -924 A/G gene in the studied groups.

\begin{tabular}{|c|c|c|c|c|}
\hline Polymorphism & $\begin{array}{l}\text { Controls } \\
(\mathbf{n}=\mathbf{1 0 0})\end{array}$ & $\begin{array}{l}\text { Patients } \\
(\mathrm{n}=100)\end{array}$ & p- value & OR $(95 \%$ CI $)$ \\
\hline \multicolumn{5}{|c|}{ IL-27-924A/G } \\
\hline \multicolumn{5}{|c|}{ Co-dominant model } \\
\hline AA & $12(12 \%)$ & $24(24 \%)$ & ----- & Ref \\
\hline AG & $63(63 \%)$ & $50(50 \%)$ & 0.02 & $0.4(0.18-0.87)$ \\
\hline GG & $25(25 \%)$ & $26(26 \%)$ & 0.14 & $0.5(0.2-1.3)$ \\
\hline \multicolumn{5}{|c|}{ Dominant Model } \\
\hline AG+GG & $88(88 \%)$ & $76(76 \%)$ & ----- & Ref \\
\hline AA & $12(12 \%)$ & $24(24 \%)$ & 0.02 & $2.3(1-4.9)$ \\
\hline \multicolumn{5}{|c|}{ Recessive Model } \\
\hline $\mathrm{AG}+\mathrm{AA}$ & $75(75 \%)$ & $74(74 \%)$ & ------ & Ref \\
\hline GG & $25(25 \%)$ & $26(26 \%)$ & 0.87 & $1(0.5-1.9)$ \\
\hline \multicolumn{5}{|c|}{ Alleles } \\
\hline $\mathrm{A}$ & $87(43.5 \%)$ & $98(49 \%)$ & ------ & Ref \\
\hline $\mathrm{G}$ & $113(56.5 \%)$ & $102(51 \%)$ & 0.14 & $0.4(0.46-1.1)$ \\
\hline
\end{tabular}

(Note: Odds ratio 95\% confidence interval (OR $95 \%$ CI)

\section{Clinical and laboratory parameters of RA patients in different IL-27 genotypes}

There was significant increase in serum level of IL-27 in AA genotype as compared to AG and GG genotypes. AA genotype had significant high DAS28 score (Table 3). There was no any variation in other parameters. 
Table 3. Clinical and laboratory parameters of RA patients in different genotypes of IL-27 -924A/G gene.

\begin{tabular}{|c|c|c|c|c|}
\hline Clinical and laboratory data & AA genotype $(n=24)$ & AG genotype $(n=50)$ & $\begin{array}{c}\text { CG genotype } \\
(\mathbf{n = 2 6})\end{array}$ & P-value \\
\hline Age & $40.62 \pm 9.37$ & $39.48 \pm 6.99$ & $37.08 \pm 4.71$ & NS \\
\hline Gender (female/male) & $22 / 2$ & $43 / 7$ & $24 / 2$ & NS \\
\hline Disease duration & $5.23 \pm 3.17$ & $4.08 \pm 2.05$ & $3.96 \pm 1.76$ & NS \\
\hline BMI & $29.09 \pm 4.79$ & $28.61 \pm 4.49$ & $27.20 \pm 3.83$ & NS \\
\hline DAS -28 & $4.14 \pm 1.37$ & $3.41 \pm 1.23$ & $3.46 \pm 1.07$ & 0.044 \\
\hline CRP & $38.81 \pm 19.99$ & $32.89 \pm 17.28$ & $32.59 \pm 15.44$ & NS \\
\hline ESR & $30.92 \pm 17.85$ & $33.72 \pm 13.22$ & $37.58 \pm 22.19$ & NS \\
\hline IL-27 & $540.79 \pm 214.98$ & $351.04 \pm 204.89$ & $309.54 \pm 124.89$ & 0.000 \\
\hline RF & $102.19 \pm 124.84$ & $68.94 \pm 61.23$ & $57.74 \pm 45.76$ & NS \\
\hline ACCP & $101.51 \pm 152.50$ & $137.36 \pm 204.97$ & $141.36 \pm 145.17$ & NS \\
\hline $\mathrm{Hb}$ & $10.46 \pm 1.08$ & $10.79 \pm 1.21$ & $10.40 \pm 1.43$ & NS \\
\hline
\end{tabular}

(Note: MBI=Body Mass Index, DAS=Disease Activity Score, CRP=C Reactive Protein, ESR=Erythrocyte Sedimentation Rate, RF=Rheumatoid Factor, $\mathrm{ACPA}=$ Anticitrullinated Protein Antibodies $I L 27=$ Interleukin 27, $\mathrm{Hb}=$ Hemoglobin.)

\section{Clinical and laboratory data of RA patients in different IL-27 alleles}

The correlation presented in Tables 4 showed that, there were significant increases of the serum IL-27 level; RF and DAS28 score parameters in RA patients with A allele of IL-27 -924 A/G gene, while ACPA levels were increased in patients with $\mathrm{G}$ allele (Table 4).

Table 4. Clinical and laboratory data of RA patients in different alleles of IL-27 -924A/G.

\begin{tabular}{llll}
\hline \multicolumn{1}{c}{ Clinical and laboratory data } & \multicolumn{1}{c}{$\begin{array}{c}\text { A allele } \\
(\mathbf{n = 9 8})\end{array}$} & \multicolumn{1}{c}{$\begin{array}{c}\text { G allele } \\
(\mathbf{n = 1 0 2})\end{array}$} & \multicolumn{1}{c}{ P-value } \\
\hline Age & $40.06 \pm 8.21$ & $38.31 \pm 6.05$ & NS \\
\hline Gender (female/male) & $87 / 11$ & $91 / 11$ & NS \\
\hline Disease duration & $4.67 \pm 2.71$ & $4.02 \pm 1.89$ & NS \\
\hline BMI & $28.86 \pm 4.60$ & $27.92 \pm 4.20$ & $\mathbf{0 . 0 4 8}$ \\
\hline DAS -28 & $3.78 \pm 1.34$ & $3.43 \pm 1.15$ & NS \\
\hline CRP & $35.91 \pm 18.75$ & $32.75 \pm 16.24$ & NS \\
\hline ESR & $32.29 \pm 15.63$ & $35.61 \pm 18.04$ & $\mathbf{0 . 0 0 0}$ \\
\hline IL-27 & $447.78 \pm 228.76$ & $330.71 \pm 170.40$ & $\mathbf{0 . 0 4 9}$ \\
\hline RF & $85.89 \pm 99.06$ & $63.45 \pm 54.02$ & $\mathbf{0 . 0 0 1}$ \\
\hline ACCP & $51.89 \pm 82.80$ & $112.68 \pm 168.47$ & NS \\
\hline Hb & $10.63 \pm 1.15$ & $10.60 \pm 1.33$ & \\
\hline
\end{tabular}

(Note: MBI=Body Mass Index, DAS=Disease Activity Score, CRP=C Reactive Protein, ESR=Erythrocyte Sedimentation Rate, RF=Rheumatoid Factor, ACPA=Anticitrullinated Protein Antibodies, IL27=Interleukin 27, Hb=Hemoglobin)

\section{Correlation between serum IL-27 levels and laboratory and clinical parameters in RA patients}

The correlation between serum levels of IL-27 and clinical and laboratory data revealed that IL-27 was positively correlated only with CRP and DAS score $(\mathrm{P}=0.001)$ (Table 5). 


\begin{tabular}{lll}
\hline Spearman's Rho Variables & $\mathbf{r}$ & $\mathbf{p}$-value \\
\hline Age & 0.039 & NS \\
\hline Disease duration & 0.131 & NS \\
\hline BMI & .063 & NS \\
\hline Hb & 0.020 & NS \\
\hline ESR & -0.052 & NS \\
\hline CRP & 0.426 & $<0.001$ \\
\hline DAS-28 score & 0.433 & $<0.001$ \\
\hline RF & 0.091 & NS \\
\hline ACPA & 0.054 & NS
\end{tabular}

(Note: MBI=Body Mass Index, DAS=Disease Activity Score, CRP=C Reactive Protein, ESR=Erythrocyte Sedimentation Rate, RF=Rheumatoid Factor, $\mathrm{ACPA}=$ Anticitrullinated Protein Antibodies, IL27=Interleukin 27, $\mathrm{Hb}=$ Hemoglobin)

\section{DISCUSSION}

IL27 has a fundamental role in differentiation and proliferation of CD4+T cells which are involved in the pathogenesis of RA. IL27 gene polymorphism may have a close link with a lot of autoimmune disorders but this link with RA still unclear (Yan et al., 2015). We observed an increased incidence of IL-27 -924 AA genotype in RA patients versus the healthy subjects $(\mathrm{P}=0.02)$. In the dominant model, the risk for development of RA was increased in individuals with AA genotype $(\mathrm{P}=0.02)$. In addition, we also observed that RA patients with AA genotype or A allele had higher DAS28 score than patients with GG genotype, telling that this genotype not only associated with RA disease but also associated with disease activity in the Egyptian populations. On contrast to our findings, Paradowska-Gorycka et al. (2014) reported that GG genotype of IL-27 gene was linked to increased possibility of RA in Polish population. The -924 A/G which is situated in the IL-27 gene promoter have an important role in controlling the process of gene expression by initiation of the transcription (Paradowska-Gorycka et al. 2016). The difference in the genotype frequencies between our results and previous findings could be elucidated by the variability of the disease, different ethnicities and small sample size.

Our study showed significant increase in the serum level of IL-27 in RA patients as compared to the healthy subjects $(\mathrm{P}=0001)$ and also there was positive linkage between IL-27 serum level and indicators of disease activity (DAS28 score and CRP). This result was in agreement with other previous studies (Lai et al., 2016; Shen et al., 2011 and Tanida et al., 2011). In contrast, some studies showed that IL-27 can have a controlling role in the immune response as it suppresses the acquired immunity and increases the number of inducible $\mathrm{T}$ cells to produce IL- 10 (Niedbala et al., 2008 \&Yoshida et al., 2009). Tanida et al. (2011) did not find any distinction between RA, osteoarthritis and healthy controls. Other stated that IL-27 may have a protective role in RA (Jones et al., 2015). It is not clear that the polymorphism of IL-27 924A/G can regulate the production of IL-27. In the current study, we found significant increase in the serum level of IL-27 in patient have AA genotype or A allele when compared to other genotypes and alleles. In contrast to this result, Tang et al. (2014) and Zhao et al. (2009) did not found any association between IL-27 gene polymorphism and the serum level of Il-27.

IL-27 has dual inflammatory influence in the pathogenesis of autoimmunity and exhibit distinguished roles in the Th cell responses (Shen et al., 2011). Presence of large amount of IL-27 at chronic inflammation sites can stimulate initial stages of the Th1 differentiation which in turn leads to arthritis (Tanida et al., 2011). More evidences for the role of IL-27 in joint inflammation as it enhances the susceptibility to arthritis by proteoglycan in murine model (Cao et al., 2008), increase the activation of STAT1 protein which was associated with proinfammatory effects in human monocytes and keratinocytes (Cao et al., 2008 and Kalliolias and Ivashkiv, 2008), and immunopathological effect by the stimulation the production of adhesion molecules and cytokines, especially TNF- $\alpha$ and IL-1 $\beta$ (Wong et al., 2010). There are some likely restrictions to our study, which could contribute results bias as the sample is not large. Although the study was involved one gene polymorphism but fortunately we did serum IL27 to assess its correlation with the gene variants. We concluded that -924 AA genotype of IL-27 gene might be a genetic risk factor for rising RA susceptibility in the Egyptian populations 
and serum levels of IL-27 could be a biomarker of the disease activity. To explore more functions of IL-27, studies on larger scale of RA patients are required.

\section{CONFLICT OF INTEREST}

All authors declare they have no conflicts of interest.

\section{REFERENCES}

Aletaha D, Neogi T, Silman AJ, Funovits J, et al. (2010). 2010 Rheumatoid arthritis classification criteria: an American College of Rheumatology/European League against Rheumatism collaborative initiative. Arthritis rheumat. 62 (9): 2569-81

Cao Y, Doodes PD, Glant TT and Finnegan A (2008). IL-27 induces a Th1 immune response and susceptibility to experimental arthritis. J. Immunol. 180:922-930. https://doi.org/10.4049/jimmunol.180.2.922

Choy EH and Panayi GS (2001). Cytokine pathways and joint inflammation in rheumatoid arthritis. Engl. J. Med.2001, 344 (12): $907-916$. https://doi.org/10.1056/nejm200103223441207

Huang ZQ, Wang JL, Pan GG and Wei YS (2012). Association of single nucleotide polymorphisms in IL-12 and IL-27 genes with colorectal cancer risk. Clin.Biochem. 45 (2): 54-59. https://doi.org/10.1016/j.clinbiochem.2011.10.004

Jones GW, Bombardieri M, Greenhill CJ, McLeod L, et al. (2015). Interleukin-27 inhibits ectopic lymphoid-like structure development in early inflammatory arthritis. J. Exp. Med. 212 (11):1793-802. https://doi.org/10.1084/jem.20132307

Kalliolias GD and Ivashkiv LB (2008). IL-27 activates human monocytes via STAT1 and suppresses IL-10 production but the inflammatory functions of IL- 27 are abrogated by TLRs and p38. J Immunol. 180 (9): 6325-6333. https://doi.org/10.4049/jimmunol.180.9.6325

Kamiya S, Okumura M, Chiba Y, Fukawa T, et al. (2011). IL-27 suppresses RANKL expression in CD4+ T cells in part through STAT3. Immunol.Lett.138 (1): 47-53. https://doi.org/10.1016/j.imlet.2011.02.022

Lai X, Wang H, Cao J, Li Y, et al. (2016). Circulating IL-27 Is Elevated in Rheumatoid Arthritis Patients. Molecules.21 (11): 1565. https://doi.org/10.3390/molecules21111565

Li CS, Zhang Q, Lee KJ, Cho SW, et al. (2009). Interleukin-27 polymorphisms are associated with inflammatory bowel diseases in a Korean population. J. Gastroenterol. Hepatol.24 (10): 1692-96. https://doi.org/10.1111/j.1440-1746.2009.05901.x

Linsley PS and Nadler SG (2009). The clinical utility of inhibiting cd28-mediated costimulation. Immunol. Rev. 229 (1): $307-321$. https://doi.org/10.1111/j.1600-065x.2009.00780.x

Niedbala W, Cai B, Wei X, Patakas A, et al. (2008). Interleukin 27 attenuates collagen-induced arthritis. Ann. Rheum. Dis. 67:1474-1479.

Paradowska Gorycka A, Raszkiewicz B, JurkowskaM, Felis-Giemza A, et al. (2014). Association of single nucleotide polymorphisms in the IL27 gene with rheumatoid arthritis. Scand. J. Immunol. 80:298-305.

Paradowska-Gorycka A, Sowinska A, Stypinska B, Grobelna MK, et al. (2016). Genetic Variants in IL-12B and IL-27 in the Polish Patients with Systemic Lupus Erythematosus. Scandinavian Journal of Immunology. 84, 49-60.

Sakaguchi S, Benham H, Cope A P and Thomas R (2012). T-cell receptor signaling and the pathogenesis of autoimmune arthritis: Insights from mouse and man. Immunol. Cell. Biol.90 (3): 277-287. https://doi.org/10.1038/icb.2012.4

Shen H, Xia L, Xiao W and Lu J (2011). Increased levels of interleukin-27 in patients with rheumatoid arthritis. Arthritis Rheum. 63 (3): 860-1. https://doi.org/10.1002/art.30180

Sprent, J and Surh CD (2011). Normal Tcell homeostasis: The conversion of naive cells into memory-phenotype cells. Nat. Immunol. 2011, $12,478-484$.

Tang Y, Wong J, Nong L, Lan C, et al. (2014). Associations of IL-27 Polymorphisms and Serum IL-27p28 Levels With Osteosarcoma Risk. Medicine. 93 (10): 1-5. https://doi.org/10.1097/md.0000000000000056

Tanida S, Yoshitomi H, Ishikawa M, Kasahara T, et al. (2011). IL-27-producing CD14 + cells infiltrate inflamed joints of rheumatoid arthritis and regulate inflammation and chemotactic migration. Cytokine.55:237-44. https://doi.org/10.1016/j.cyto.2011.04.020

Tao YP, Wang WL, Li SY, Zhang J, et al. (2012). Associations between polymorphisms in IL-12A, IL-12B, IL-12Rbeta1, IL-27 gene and serum levels of IL-12p40, IL-27p28 with esophageal cancer. J. Cancer Res. Clin. Oncol. 138 (11): 1891-900. https://doi.org/10.1007/s00432-012-1269-0 
Trinchieri G (2003). Interleukin-12 and the regulation of innate resistance and adaptive immunity. Nat. Rev. Immunol. 3 (2): $133-46$. https://doi.org/10.1038/nri1001

Wong CK, Chen DP, Tam LS, Li EK, et al. (2010). Effects of inflammatory cytokine IL-27 on the activation of fibroblast-like synoviocytes in rheumatoid arthritis. Arthritis Res. Ther. 12 (4): R129. https://doi.org/10.1186/ar3067

Yan J, Shang X and Rong X (2015). Relationship between IL-27 gene polymorphism and susceptibility of rheumatoid arthritis in Chinese Han population Int. J. Clin. Exp. Med. 8 (4):6262-6266.

Yoshida H, Nakaya M and Miyazaki Y (2009). Interleukin 27: A double-edged sword for offense and defense. J. Leukoc. Biol. 86 (6): 1295 1303. https://doi.org/10.1189/jlb.0609445

Zhang Z, Zhou B, Wu Y, Gao Q, et al. (2014). Prognostic value of IL-2 polymorphisms and the susceptibility to epithelial ovarian cancer in a Chinese population. Immunogenetics.66 (2): 85-92. https://doi.org/10.1007/s00251-013-0753-2

Zhao B, Meng LQ, Huang HN, et al. (2009). A novel functional polymorphism, 16974 A/C, in the interleukin-12-3' untranslated region is associated with risk of glioma. DNA Cell Biol. 28: 335-41. https://doi.org/10.1089/dna.2008.0845 